\title{
Follicles explanted from pentobarbitone-treated rats provide a model for atresia*
}

\author{
Ruth H. Braw and A. Tsafriri \\ Department of Hormone Research, The Weizmann Institute of Science, Rehovot, Israel
}

\begin{abstract}
Summary. Graafian follicles from rats treated for 1 or 2 days with pentobarbitone sodium (Nembutal) were similar in appearance to pro-oestrous preovulatory follicles, but after 3 or 4 days of treatment early atretic changes were recognized. Ovulatory efficiency decreased to $88,70,52$ and $31 \%$ after $1,2,3$ and 4 days of treatment, respectively. The mean \pm s.e.m. rate of accumulation (ng/follicle/24 h) of progesterone, androstenedione and oestradiol was $3.6 \pm 0.7,4.0 \pm 0.3$ and $18.9 \pm$ 3.9 respectively in preovulatory follicles and $10.2+1.7,0.9 \pm 0.1$ and $1.9 \pm 0.4$ respectively in follicles explanted from rats treated for 4 days with Nembutal. Addition of LH $(5 \mu \mathrm{g} / \mathrm{ml})$ to the culture medium stimulated steroid accumulation by both types of follicles. Thus atretic follicles are characterized by impaired androgen and oestradiol formation. Addition of testosterone $(1 \mu \mathrm{g} / \mathrm{ml})$ to the culture medium increased the accumulation of oestradiol by atretic follicles. It is inferred that the early stages of atresia of rat follicles are distinguished by a deficiency in the activity of enzymes responsible for the conversion of progesterone to androgens that can serve as substrates for aromatization.
\end{abstract}

\section{Introduction}

The vast majority of the oocyte and follicular populations undergoes atresia rather than ovulation (reviewed by Byskov, 1978). Nevertheless, the factors which determine whether a follicle will ovulate or undergo atresia are still obscure. This is probably because incipient atresia is recognized only in retrospect. Therefore the development of an animal model in which atresia can be produced in a synchronized follicle population offers an attractive approach to the study of various aspects of atresia.

The administration of pentobarbitone sodium on the afternoon of pro-oestrus blocks the preovulatory surge of gonadotrophins and ovulation is prevented (Everett \& Sawyer, 1950; Naftolin, Brown-Grant \& Corker, 1972; Ayalon, Tsafriri, Lindner, Cordova \& Harell, 1972; Butcher, Collins \& Fugo, 1974; Ashiru \& Blake, 1978). Daily administration of the drug, starting on the day of pro-oestrus, results in atresia of Graafian follicles within 3 days (Everett \& Sawyer, 1950). Atresia induced in this way may be suitable for study of the physiological changes within the follicle before the first morphological signs of atresia can be observed. However, in this model only atresia of mature Graafian follicles which have attained full responsiveness to $\mathrm{LH}$ can be studied.

The purpose of this study was to examine the relationship between follicular histology, the ability of the follicle to ovulate in response to hCG and the pattern of follicular steroidogenesis in vitro in animals treated with pentobarbitone sodium.

* Presented as the Arthur Walpole Memorial Lecture to the Society of the Study of Fertility, Glasgow, 1979. 


\section{Materials and Methods}

\section{Animals}

The Wistar-derived rats were from the departmental colony and were housed in airconditioned rooms with light between 05:00 and 19:00 h. Pelleted food and water were always available. The animals were 4 months old and daily vaginal smears were taken to confirm that each had shown at least two normal 4-day cycles immediately before the experiment.

Pentobarbitone sodium (Nembutal, Abbott; $30 \mathrm{mg} / \mathrm{kg}$ body weight) was injected intraperitoneally on the day of pro-oestrus between 13:40 and 14:00 h and on the next 3 days between 13:30-14:00 and 15:40-16:00 h. The critical period for blockage of ovulation by Nembutal in our colony is between 13:30 and 16:30 h (Tsafriri \& Kraicer, 1972). Immediately after the last injection of Nembutal, some of the rats (5-10/group) were given an i.p. injection of 4 i.u. hCG (Pregnyl, Organon). Ovulation was checked by expressing and counting tubal ova $16-18 \mathrm{~h}$ after $\mathrm{hCG}$.

\section{Culture of follicles}

Animals were killed by cervical dislocation between 08:00 and 12:00 $\mathrm{h}$ on the day after the last Nembutal injection. Graafian follicles were explanted from the ovaries and cultured as previously described (Tsafriri, Lindner, Zor \& Lamprecht, 1972). Preovulatory follicles explanted between 08:00 and 12:00 on the day of pro-oestrus from untreated females were used as normal controls. Each dish contained 2-3 follicles, and ovine LH (NIH-LH-S18; $5 \mu \mathrm{g} / \mathrm{ml}$ ), FSH (NIH-FSH-S $11 ; 10 \mu \mathrm{g} / \mathrm{ml}$ ) or testosterone (Ikapharm; $1 \mu \mathrm{g} / \mathrm{ml}$ ) were added to the medium as indicated. The gonadotrophins were dissolved in $0.9 \%(\mathrm{w} / \mathrm{v}) \mathrm{NaCl}$ and testosterone in absolute ethanol before dilution in the medium. The final ethanol concentration of $0.1 \%$ had no effect on steroid accumulation.

The medium was collected after $6 \mathrm{~h}$, replaced by fresh medium, and collected again after further incubation for $18 \mathrm{~h}$.

\section{Steroid assays}

The amounts of progesterone, androstenedione, testosterone and oestradiol-17 $\beta$ in the medium were determined by radioimmunoassays as described by Lindner \& Bauminger (1974). Steroids were extracted from the medium with 8 volumes ether and the ether extracts were evaporated to dryness under $\mathbf{N}_{2}$. The residue was redissolved in ethanol and portions were taken for steroid determination. Well characterized and specific antisera against progesterone, androstenedione, testosterone and oestradiol- $17 \beta$ were obtained by immunizing rabbits with albumin conjugates of the following steroid derivatives: progesterone-11 $\alpha$-hemisuccinate, the 7 carboxyethylthioethers of androstenedione and testosterone and the 6-carboxymethyl oxime of oestradiol (Bauminger, Kohen \& Lindner, 1974; Kohen, Bauminger \& Lindner, 1975). The major cross-reactions of the anti-progesterone and anti-androgen sera were with the corresponding $5 \alpha$-pregnane and $5 \alpha$-androstane compounds and the anti-oestradiol sera crossreacted markedly with 6-oxo- and 6-hydroxy-oestradiol (Bauminger et al., 1974). The sensitivities and intra- and inter-assay coefficients of variation for the progesterone, androstenedione, testosterone and oestradiol assays were $15,30,30$ and $20 \mathrm{pg} / \mathrm{ml}$ and 2, 3, 4 and $3 \%$, and $20,16,18$ and $20 \%$ respectively.

The statistical differences between groups were calculated by Student's $t$ test. 


\section{Histological procedures}

Some of the ovaries (3-4/group) were used for morphological examination. They were fixed in Bouin's solution, dehydrated, embedded in paraffin wax and cut serially at $7 \mu \mathrm{m}$. Sections were stained with haematoxylin and eosin and all the large Graafian follicles were examined for signs of atresia.

\section{Results}

\section{Morphology of the Graafian follicles after Nembutal treatment}

Follicles from rats after 1 or 2 days of Nembutal treatment were similar in appearance to the preovulatory follicles. They contained an oocyte in the dictyate stage, a few dividing granulosa cells, and no pyknotic granulosa cell nuclei.

After 3 and 4 days, most of the follicles contained an oocyte in the dictyate stage. However, in some of the oocytes meiosis-like changes, such as chromosomes at metaphase or the presence of a polar body, could be observed after 4 days of Nembutal treatment. Pyknotic nuclei were present in the granulosa layer but mitotic figures could also still be seen. The granulosa layer and basement membrane appeared puckered. Hence, according to our classification (Braw \& Tsafriri, 1980) most of the large follicles had reached Stage I of atresia by Day 3, and Stages I and II of atresia by 4 days after the start of Nembutal treatment.

\section{Induction of ovulation by $h C G$}

The percentage of rats ovulating following hCG administration was only slightly decreased following Nembutal treatment but the number of ova shed and the ovulatory efficiency was significantly affected (Table 1).

Table 1. Induction of ovulation by hCG in pentobarbitone-treated rats

\begin{tabular}{lccccc}
\hline & \multicolumn{5}{c}{ Days of pentobarbitone sodium treatment } \\
\cline { 2 - 6 } & 0 & 1 & 2 & 3 & 4 \\
\hline No. of rats treated & 12 & 10 & 10 & 5 & 10 \\
No. of rats ovulating (\%) & $12(100)$ & $9(90)$ & $8(80)$ & $4(80)$ & $7(70)$ \\
No. of ova shed/rat treated & $11.0 \pm 0.6$ & $9.7 \pm 1 \cdot 1$ & $7 \cdot 7 \pm 1 \cdot 4^{*}$ & $5 \cdot 8 \pm 1 \cdot 7^{* * *}$ & $3 \cdot 4 \pm 1 \cdot 3^{* * *}$ \\
Ovulatory efficiency (\%) $\dagger$ & 100 & 88 & $70^{* *}$ & $53^{* *}$ & $31^{* * *}$ \\
\hline
\end{tabular}

$* P<0.05 ; * * P<0.01 ; * * P<0.001$ compared with Day 0 .

$\dagger($ No. of ova/treated rat $\times 100) /($ no. of ova/control rat $)$.

\section{Follicular steroidogenesis}

The changes in steroidogenesis after 6 and $24 \mathrm{~h}$ of culture were similar and therefore only the $24 \mathrm{~h}$ data are illustrated and discussed.

Preovulatory follicles incubated in LH-free medium accumulated predominantly oestradiol$17 \beta$, while production of progesterone, androstenedione and testosterone was low. In follicles from Nembutal-treated animals the production of oestradiol-17 $\beta$, androstenedione and testosterone was reduced, while progesterone accumulation increased (Text-fig. 1), being significantly higher on Day $1(P<0.01)$ and on Days 2,3 and $4(P<0.001)$. The ratio of oestradiol-17 $\beta /$ progesterone accumulation after $24 \mathrm{~h}$ of incubation was 5 for the preovulatory follicles, 1 for follicles after 1 day and 0.2 after 4 days of Nembutal treatment. 


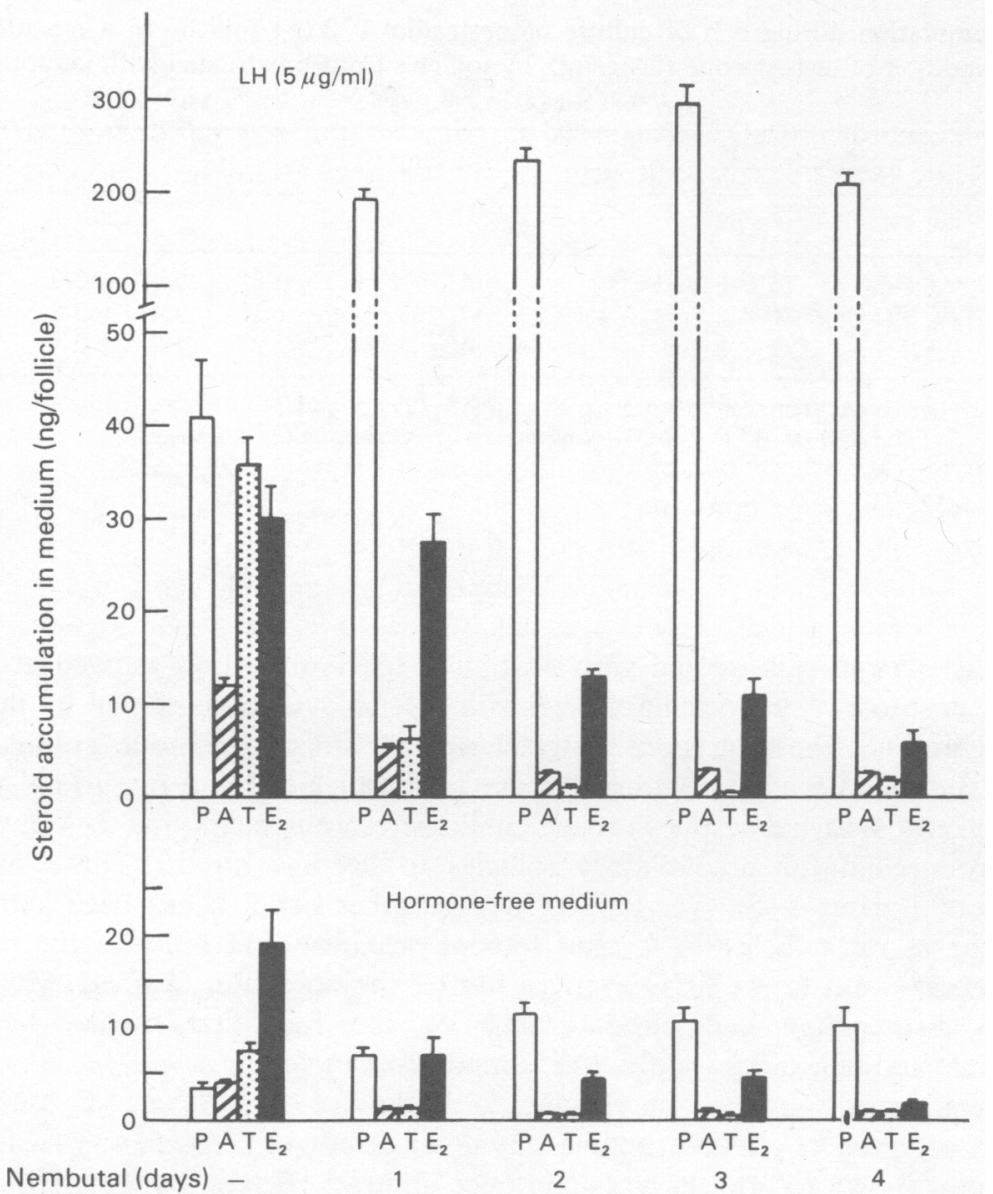

Text-fig. 1. Accumulation of progesterone (P), androstenedione (A), testosterone $(T)$ and oestradiol-17 $\beta\left(E_{2}\right)$ by follicles from pentobarbitone sodium-treated rats during $24 \mathrm{~h}$ of culture in the hormone-free medium and in medium containing $5 \mu \mathrm{g} \mathrm{LH} / \mathrm{ml}$. Each bar represents the mean \pm s.e.m. of 6-10 determinations. The data are expressed as ng steroid/follicle; the wet weight of a follicle is about $150 \mu \mathrm{g}$ with $15-20 \mu \mathrm{g}$ protein/follicle.

Addition of $\mathrm{LH}$ to the culture medium increased steroid production in all types of follicles. Progesterone accumulation was significantly higher $(P<0.001)$ after Nembutal treatment than in the preovulatory follicles. A $50 \%$ or more reduction in formation of oestradiol-17 $\beta$, testosterone and androstenedione was observed in the follicles from rats that had received Nembutal.

\section{Oestradiol-17 $\beta$ formation in the presence of testosterone}

As shown in Table 2, testosterone $(1 \mu \mathrm{g} / \mathrm{ml})$ in the medium significantly increased production of oestradiol-17 $\beta$ in preovulatory follicles and in follicles from Nembutal-treated rats $(P<0.05)$. Addition of $\mathrm{LH}$ in the presence of testosterone increased the accumulation of oestradiol-17 $\beta$ in follicles from Nembutal-treated rats and restored oestradiol levels to those of untreated preovulatory follicles. Although FSH increased oestradiol-17 $\beta$ accumulation, values on Day 4 were not as high as those on the day of pro-oestrus. 
Table 2. Accumulation during $6 \mathrm{~h}$ of culture of oestradiol-17 $(\mathrm{ng} /$ follicle) in a medium without $(-\mathrm{T})$ or with $(+\mathrm{T})$ addition of testosterone $(1 \mu \mathrm{g} / \mathrm{ml})$, by follicles from rats treated with pentobarbitone sodium for 0,1 or 4 days

\begin{tabular}{|c|c|c|c|c|c|c|}
\hline \multirow{2}{*}{$\begin{array}{c}\text { Other } \\
\text { medium } \\
\text { additions }\end{array}$} & \multicolumn{2}{|c|}{ Day 0} & \multicolumn{2}{|c|}{ Day 1} & \multicolumn{2}{|c|}{ Day 4} \\
\hline & $-T$ & $+T$ & $-\mathbf{T}$ & $+\mathrm{T}$ & $-\mathrm{T}$ & $+\mathrm{T}$ \\
\hline $\begin{array}{l}\text { None } \\
\text { LH } \\
\text { FSH }\end{array}$ & $\begin{array}{r}7.5 \pm 0.2 \\
26.2 \pm 3.0 \\
25.1 \pm 2.5\end{array}$ & $\begin{array}{l}15.9 \pm 2.0^{*} \\
20.8 \pm 1.4 \\
21.7 \pm 2.3\end{array}$ & $\begin{array}{r}3.1 \pm 0.4 \\
19.6 \pm 1.7 \\
23.2 \pm 1.1\end{array}$ & $\begin{array}{r}9.7 \pm 0.8^{*} \\
32.6 \pm 2.1^{*} \\
44.5 \pm 3.2^{*}\end{array}$ & $\begin{array}{l}1.0 \pm 0.2 \\
4.7 \pm 0.8 \\
7.4 \pm 0.4\end{array}$ & $\begin{aligned} 9.8 & \pm 3 \cdot 0^{*} \\
16.9 & \pm 2 \cdot 8^{* *} \\
10.2 & \pm 2.4\end{aligned}$ \\
\hline
\end{tabular}

Values represent mean \pm s.e.m. of 3-10 cultures and 2-3 follicles/culture.

* $P<0.01 ;{ }^{* *} P<0.001$ compared with corresponding $-\mathrm{T}$ values.

\section{Discussion}

Graafian follicles from rats treated with Nembutal for 1 or 2 days showed no morphological signs of atresia. Most of these follicles were still able to ovulate as shown by their response to hCG administration. The first morphological sign of atresia (pyknotic granulosa cell nuclei) appeared in the follicles after treatment of the rats with Nembutal for 3 or 4 days and these follicles gave only a partial response to hCG. It therefore appears that 3-4 days of Nembutal treatment are needed for preovulatory follicles to become atretic. This confirms previous observations of Everett \& Sawyer (1950). On the other hand, it has been shown that atretic changes occur in rat follicles $19 \mathrm{~h}$ after hypophysectomy and most of the follicles of such animals fail to respond to the hCG even $12 \mathrm{~h}$ after the operation (Talbert, Meyer \& McShan, 1951). This discrepancy can be explained by the fact that, unlike hypophysectomy, pentobarbitone sodium blocks only the gonadotrophin surge while basal levels of serum gonadotrophins remain unaffected (Daane \& Parlow, 1971; Ashiru \& Blake, 1978). The presence of basal levels of gonadotrophins may delay atresia of preovulatory follicles and PMSG has in fact been shown to prevent atresia in mice and rats (Peters, Byskov, Himelstein-Braw \& Faber, 1975; Peters, 1979; Braw \& Tsafriri, 1980).

The present study shows that the steroidogenic activity of atretic follicles is markedly different from that of preovulatory ones. Furthermore the results indicate that changes in steroid secretion occur very early during the atretic process, i.e. before morphological signs of atresia can be observed. Thus after 1 day of Nembutal treatment progesterone accumulation was doubled in gonadotrophin-free medium and increased 4-6-fold in response to the addition of LH (Text-fig. 1). Whether this increase in progesterone accumulation is related to atretic changes within the follicle or is due to another, yet undetermined, process remains to be established. An increase in progesterone accumulation has been demonstrated in atretic sheep follicles (Moor, Hay, Dott \& Cran, 1978; Hay, Moor, Cran \& Dott, 1979).

Follicular oestradiol synthesis decreased with the length of Nembutal treatment. Thus atretic follicles after 4 days of Nembutal treatment accumulated only one-fifth as much oestradiol as did preovulatory follicles. A similar decrease in oestradiol accumulation was observed by Moor $e t$ al. (1978) in cultures of sheep atretic follicles. Likewise the oestradiol content of mare atretic follicles was markedly reduced compared to that of healthy follicles (Condon, Ganjam, Kenney \& Channing, 1979).

In cultures of rat atretic follicles androgen secretion was reduced although Moor et al. (1978) found a 2-3-fold increase for sheep follicles in culture. Moor et al. (1978) concluded that during atresia of sheep follicles aromatizing enzymes were affected. However, our results with rats show that addition of testosterone increased oestradiol production to levels similar to those of untreated preovulatory follicles (Table 2). In the rat, therefore, one or more of the enzymes 
responsible for the synthesis of androgen from progesterone, rather than aromatizing enzymes, seem to be affected during early atretic changes. The discrepancy between our results and those of Moor et al. (1978) may be due to species differences and/or to the stage of atresia at which the follicles were explanted. It is possible that the rat follicles were explanted at an earlier stage of atresia.

Atretic rat follicles responded to $\mathrm{LH}$ with increased steroidogenesis which was due entirely to enhanced progesterone synthesis because androgen and oestradiol accumulation was only oneninth that seen in preovulatory follicles. These results indicate that in early stages of Nembutalinduced follicular atresia in the rat, steroidogenic responsiveness to LH was not impaired.

Our preliminary study of atretic follicles following hypophysectomy indicate changes in steroidogenesis similar to those observed in the follicles following Nembutal treatment, i.e. an increase in progesterone and a decrease in androgen and oestradiol secretion. However, these changes appeared much earlier as compared to pentobarbitone-treated rats. Thus it appears that pentobarbitone treatment brings about changes analogous to these in atretic follicles obtained by total gonadotrophin deprivation, but the process of atresia is slowed down in the former. The occurrence of atresia in rats treated with pentobarbitone sodium will clearly be useful for further study of extragonadal and follicular factors involved in the atretic process.

We thank the NIAMDD for the LH and FSH preparations; Professor H. R. Lindner for his interest; Dr F. Kohen and Dr A. Nimrod for advice; Mrs A. Tsafriri for skilful technical assistance; and $\mathrm{Mr}$ S. Yosef for care of the animals. The contribution of R.H.B. constitutes part of the requirements for the Ph.D. degree of the Feinberg Graduate School of the Weizmann Institute of Science. The work was generously supported by the Population Council, New York, and the Ford Foundation.

\section{References}

Ashiru, O.A. \& Blake, C.A. (1978) Restoration of the periovulatory follicle-stimulating hormone surges in sera by luteinizing hormone releasing hormone in phenobarbital-blocked rats. Life Sciences 23, 15071514.

Ayalon, D., Tsafriri, A., Lindner, H.R., Cordova, T. \& Harell, A. (1972) Serum gonadotrophin levels in prooestrous rats in relation to the resumption of meiosis by the oocytes. J. Reprod. Fert. 31, 51-58.

Bauminger, S., Kohen, F. \& Lindner, H.R. (1974) Steroids as haptens: optimal design of antigens for the formation of antibodies to steroid hormones. $J$. Steroid Biochem. 5, 739-747.

Braw, H.R. \& Tsafriri, A. (1980) Effect of PMSG on follicular atresia in the immature rat ovary. $J$. Reprod. Fert. 59, 267-272.

Butcher, R.L., Collins, W.E. \& Fugo, N.W. (1974) Altered secretion of gonadotropins and steroids resulting from delayed ovulation in the rat. Endocrinology 96, 576-586.

Byskov, A.G. (1978) Follicular atresia. In The Vertebrate Ovary, pp. 533-562. Ed. R. E. Jones. Plenum Publishing Corporation, New York.

Condon, W.A., Ganjam, V.K., Kenney, R.M. \& Channing, C.P. (1979) Follicular atresia in the mare. In Ovarian Follicular Development and Function, pp. 75-78. Eds A. R. Midgley \& W. A. Sadler. Raven Press, New York.
Daane, T.A. \& Parlow, A.I. (1971) Periovulatory patterns of rat serum follicle stimulating hormone and luteinizing hormone during the normal estrous cycle: effect of pentobarbital. Endocrinology 88, 653-663.

Everett, J.W. \& Sawyer, C.H. (1950) A 24-hour periodicity in the "LH-release apparatus" of female rats, disclosed by barbiturate sedation. Endocrinology 47, 198-218.

Hay, M.F., Moor, R.M., Cran, D.G. \& Dott, H.M. (1979) Regeneration of atretic sheep ovarian follicles in vitro. J. Reprod. Fert. 55, 195-207.

Kohen, F., Bauminger, S. \& Lindner, H.R. (1975) Preparation of antigenic steroid-protein conjugator. In Steroid Immunoassay, pp. 11-32. Eds E. H. D. Cameron, S. G. Hillier \& K. Griffiths. Alpha-Omega Publishing Ltd, Cardiff.

Lindner, H.R. \& Bauminger, S. (1974) Production and characterization of antisera to steroid hormones. In Proc. Workshop on Gonadotrophins and Gonadal Steroids, pp. 197-227. Eds P. G. Crosignani \& V. H. T. James. Academic Press, New York.

Moor, R.M., Hay, M.F., Dott, H.M. \& Cran, D.G. (1978) Macroscopic identification and steroidogenic function of atretic follicles in sheep. J. Endocr. 77, $309-318$.

Naftolin, F., Brown-Grant, K. \& Corker, C.S. (1972) Plasma and pituitary luteinizing hormone and 
peripheral plasma oestradiol concentrations in the normal oestrous cycle of the rat and after experimental manipulation of the cycle. J. Endocr. 53, 17-30.

Peters, H. (1979) Some aspects of early follicular development. In Ovarian Follicular Development and Function, pp. 1-13. Eds A. R. Midgley \& W. A. Sadler. Raven Press, New York.

Peters, H., Byskov, A.G., Himelstein-Braw, R. \& Faber, M. (1975) Follicular growth: the basic event in the mouse and human ovary. J. Reprod. Fert. 45, 559566.
Talbert, G.B., Meyer, R.K. \& MeShan, W.H. (1951) Effect of hypophysectomy at the beginning of proestrus on maturing follicles in the ovary of the rat. Endocrinology 49, 687-694.

Tsafriri, A. \& Kraicer, P.F. (1972) The time sequence of ovum maturation in the rat. J. Reprod. Fert. 29, 387393.

Tsafriri, A., Lindner, H.R., Zor, U. \& Lamprecht, S.A. (1972) In vitro induction of meiotic division in follicle-enclosed rat oocytes by $\mathrm{LH}$, cyclic AMP and prostaglandin $\mathrm{E}_{2}$.J. Reprod. Fert. 31, 39-50.

Received 13 July 1979 